\title{
Narrative Based Medicine for healthcare professionals and cancer patients
}

\author{
Valerio Ferro Allodola* \\ “eCampus” University, Milan, Italy
}

*Corresponding author: Valerio Ferro Allodola, Adjunct Professor, "eCampus" University, Milan, Italy.

Received Date: March 17, 2020

Published Date: March 26, 2020

\section{Evidence Based Medicine and Narrative Based Medicine}

Unlike the Evidence Based Medicine (EBM) approach, which tends not to consider the particularity of the subject, understood as unicum, in recent years a new "sensitivity" has spread in the Medical Faculties of many countries - European and non-European - and a different way of understanding medical-health practice: Narrative Based Medicine (NBM). This supports the need for social and health workers to learn to pay attention to patient stories and understand their emotional experience, but also to reflect on themselves, their emotions in confronting the disease and how they affect perceptions and on clinical practice. Rita Charon, director of magazine "Literature and Medicine" (Columbia University, USA) and leading exponent of the Narrative Medicine movement, supports the relevance, in the training of health professionals, of the narrative element, defined as a set of listening skills , analyze, interpret, share stories. The narration of one's illness, if on the one hand, helps the patient to rationalize and put order in the chaos of emotions he is experiencing, to transfer anxieties, fears, fears, to acquire greater self-control and to find meaning in his own experience of illness, on the other hand helps doctors to grow in humanity, to the exercise of analysis and self-criticism, avoiding the risk that compressed emotions may turn into a cynical detachment or reappear, later, in the form of frustration, burn -out, etc. Narrative appears on the scene when medicine, having reached extraordinary technological development goals, seems to lose its effectiveness precisely in the relationship with the patient and, consequently, in the identification and management of those states of suffering that are not pathology but they are no longer health, building a bridge between science and the worlds of life [1]. Narrative Medicine stimulates not only a process of existential and relational anamnesis of the patient's experience, but also the co-construction between doctor and patient of the meaning of the patient's experience and the progressive opening of biomedicine to the contributions of complementary medicines, in addition to growth a fruitful dialogue with pedagogy, sociology, psychology and anthropology. The narrativity in medicine is acquiring a role of increasing importance as a method to investigate and make hypotheses, as an investigation to collect new data, as a theory that acts as a meeting point between professionals who start from different conceptual settings and thinking traditions [2].

In recent years, various theoretical approaches in the psychopedagogical field have underlined the importance of tools such as narration and autobiography for the construction of the Self. When the person narrates himself and his personal history, he gives greater significance to his actions and presents himself to others, in the way he deems most appropriate for a specific implementation. In this way, defining his future self, he organizes his own conduct. Talking about EBM or NBM therefore means passing through different ways of defining the body, disease, malaise, care, function of care, quality of care etc., It means going through two different "epistemologies"[3-6]. The emergence of narrative-based medicine, often in controversy as opposed to evidence-based medicine, cannot fail to be a sign of cultural change within the system of investigation, diagnosis and treatment of biomedicine. There are three fundamental aspects that provide for NBM:

1. The observation of the subjectivity of the disease that leads the whole meeting of the patient in his reality;

2. The interaction between malaise (illness) and physiology (disease), for example through links with the psych immune 
system, which requires the overcoming of organic-systemic, organic-functionalist, normative functionalist and conflictual models, using the construction of a point of sociological, relational and connectionist view, able to modify the cultural settings of health / disease;

3. The emergence of a new post-modern medical epistemology of re-appropriate greeting, by patients, with greater attention to people and their identity, including genetics.

4. Here then the training - both initial and ongoing - occupies a particular place especially for operators in support of care, for doctors in particular, urged to take on the problems of their patients not only in a strictly biological key, but also falling into the meaning that the disease has not only for the patient, but also for his family.

As Bonadonna [7] states, "modern doctors like 'ancient' doctors must know that patients are not a mere collection of symptoms and signs of disease, of organic and psychological dysfunctions; they are first and foremost human beings, apprehensive, lost and hopeful, eager for comfort, help, reassurance. It is therefore essential to balance health science with a strong recovery of the art of healing. The doctor must be able to master technology and not become a slave to it. Medicine is an art that never ends. "NBM - of course does not want to replace itself or be an alternative to EBM. In an article in the British Medical Journal - more than a decade ago Greenhalgh \& Hurwitz [8] said: "Why study the narratives? In the diagnostic meeting, the description is the phenomenal form in which the patient experiences health; encourages empathy and promotes understanding between the doctor and the patient; allows the construction of clues and analytical categories useful for the therapeutic process; suggests the use of a holistic method. In research, narrative medicine helps to develop a patient-centered agenda and generate new hypotheses". The NBM is therefore, first of all, a "proposal" of approach; the result of a co-construction work between patient and professional in which the latter tries to grasp not only the causes but also the reasons and the experience of the disease. Furthermore, narrative medicine can improve the quality of care especially for the following reasons:

1. allows you to get closer to the "reasons" of the patient, facilitating the exercise of empathy;

2. by comparing the point of view of the various operators, it facilitates team building, reducing inefficiencies and errors;

3. helps to reflect on oneself, on daily clinical practice, promoting self-care, preventing burn-out and constantly reconfiguring one's professional epistemology.

Finally, narrative medicine produces sustainability. Through a "cognitive listening" [9], not conditioned by early starting hypotheses, reflection on the said / unspoken, the written / unwritten, helps to understand the patient's point of view, improving the care style. Any relationship interrupted due to a lack of humanity and competence between the therapist and the patient is, moreover, an anomaly of quality and an unsustainable waste for Health [10].

\section{Methodologies and Tools of NBM}

Starting from the assumption that the doctor and the health professional must combine two requisites, namely the technical skills (expertise) and the relational ones, in the contexts of the care, therefore, dialogic, narrative and reflective competence take on importance. The guiding idea of the training training projects is to trigger in the operators a path of reflective practice on their knowledge, on their idea of health, on the contrast/complementarity between evidence-based knowledge (EBM) and on the narration of experiences and of life prospects (NBM). The centrality of the operator in the educational relationship (educating to a lifestyle) and in the care relationship (taking charge of) then becomes the meaning of both prevention and treatment. But this passes through the enhancement of [narrative] and reflective strategies that allow the operator to enter into a relationship with his own thinking and with his own "submerged" heritage of knowledge that reflects his personal and professional history. It is through this personal "personal knowledge" that he acts as an educator. The 'unmasking' of the operator's implicit representations and ideas, therefore - activated in moments of specific training through narrative workshops and reflective practice - is the expression of how health professionals "see themselves, their task, their degree of abstraction or involvement, the preferential ways of relating and reflective awareness that accompany the personal knowledge of the profession" [11].

As regards the "repertoire of instruments", typical of NBM, are: observation, "cognitive listening" and transcription of patient stories by healthcare professionals;

1. reflective practice, activated by specific self-reflection narrative workshops, aimed at promoting "transformative learning" [12]. It is possible to use films or film sequences to stimulate reflection (eg in the case of cancer patients, for the doctor and the health professional, a training course can be envisaged starting from the film "Wit", by Mike Nichols, USA, 2001).

2. shared and consensual reading of patient and professional diaries;

3. The parallel folder or "parallel chart" (where all other information, moods and thoughts not foreseen in a medical chart are transcribed) [13].

\section{Why Narrative Medicine can help Healthcare} Professionals and Cancer Patients

The storytelling can certainly represent, as evidenced by the scientific literature that has deepened it, an added value for the 
understanding of patients, an understanding that transcends the "data" and the "symptom" and deepens it from the point of view of the illness, for the realization of the diagnosis and the formulation of the therapy. This is also a valuable opportunity to give voice to those who normally do not have them, even though they are in fact the protagonist, that is, to the patient, or to those around them (caregivers). In addition, this way of remembering one's own care experience is for the patient, as well as being more accessible than the drafting of a scientific article that provides for the processing of data on his own case history, an opportunity for immediate meeting and comparison with other operators, because filtered by one's sensitivity. The basic concept is that of "attention" to the other not only as a body carrying symptoms and pathologies or as a set of organs on which to intervene, but as a person carrying "experiences" and emotions (illness). In order to be practiced, illness requires two fundamental tools: time and attention. Time, however, must be managed and not wasted. As pointed out by Hayden White in 1981, the narrative can be considered as "the solution of the problem of how to translate knowledge into saying, modeling human experience in a form that is assimilable to meaning structures that are generally human rather than specifically cultural. We may not be able to fully understand the specific thought patterns of another culture, but we have relatively less difficulty understanding a story from another culture, however exotic this culture appears to us. As Gadamer [14] reminds us, clinical practice is based on a dialogical dimension that is realized in a discourse on the patient and on the disease that does not want to be just an explanation, but that is also an understanding and production of intersubjective meaning. We can say that the Narrative Medicine moves in two directions: towards the patient, with collective or individual contexts in which to narrate and towards the operator, who experiences the narration of the self and builds a repertoire of narrative experiences. It is not possible to work with the history of the other without first analysing one's own. Narrative Medicine "stimulates, not only a process of existential and relational anamnesis of the patient's experience, but also the co-construction between doctor and patient of the meaning of the experience of the disease. The narrative forces you to bend over the patient's emotional world in a logic of sharing, which refers not to the diversity of the roles of the patient, but to the common human dimension of existence. The treatment process then becomes a construction of meanings and clinical practice becomes aware of its own educational dimension, full of implications on the ethical level" [15].

In fact, the narrative activity on "clinical cases" generates theories from practice and allows the meeting in the care relationship of "two stories", contextualising them in a "therapeutic relationship". The narrative experience allows us to work on our learning by transforming it. Transforming, Freeman [16] reminds us, means that we have to give up old values, habits, skills and beliefs to make room for new ones. To indicate this process, Freeman uses the term "de-learning". This is declined into "learning to take responsibility for cognitive acts and care choices and choose whether to adhere exclusively to a quantitative epistemology
(EBM), which measures effectiveness and performance, or whether to adhere to a constructivist epistemology (NBM) that acts as selfregulation"[17].

\section{Conclusion}

Disease has two faces: on the one hand it expresses itself in an "objectified body", it can be described through rigorous experimental and quantitative research strategies, removed or modified with technical interventions, on the other it is a subjective experience lived by the individual and his family and by the doctor himself, which can be known through equally rigorous qualitative research strategies and understood through reflective methodologies that can influence the prognosis and the course (e.g. taking charge) [18]. Attention to the patient's illness - especially cancer patient - attributes value to symptoms in the personal context, as a subjective feeling of feeling good / bad. In particular of "perceived quality of life". Talking about health means "understand the meaning of particular or daily events, the consequent adaptations or mismatches activated and the desires and expectations of a subject who finds himself inserted in a given environment. Speaking of health, ultimately, means talking about the life of persons, not only for what they are but, above all, for how the life is perceived and lived" [19].

\section{Acknowledgment}

None.

\section{Conflict of Interest}

No conflict of interest.

\section{References}

1. Ferro Allodola V, Canocchi E (2011) Prevenzione e cura. Lavorare con le rappresentazioni, Pensa Multimedia, Lecce.

2. Ivi, Spain.

3. de Mennato P (2008) Nuovi modelli di apprendimento nelle scienze della salute per rispondere alla complessità delle cure. Congresso Nazionale SIPEM. Tutor $8(1 / 2)$ : 1-8.

4. de Mennato P (2009) Apprendimento trasformativo degli stili di vita. In: Blezza F (Ed.) Pedagogia della prevenzione, Centro Scientifico Editore, Torino.

5. de Mennato P (2010) Pensiero paradigmatico e pensiero narrativo nella formazione medica. In: Lippi D (Ed.) Specchi di carta. Percorsi di lettura in tema di Medicina Narrativa, Clueb, Bologna.

6. de Mennato $P$ (2011) La complessità del pensiero di cura. In: De Mennato P, Orefice C, Branchi S (Eds.) Educarsi alla "cura”. Un itinerario riflessivo tra frammenti e sequenze, Pensa Multimedia, Lecce.

7. Bonadonna G (2011) Il rapporto medico-paziente: il cuore dell'arte della medicina. In: Abstract Book $3^{\circ}$ Convegno nazionale Medicina narrativa e malattie rare, ISS, Rome, p. 67.

8. Greenhalgh T, Hurwitz B (1999) Narrative based medicine: why study narrative? British Medical Journal, 318: 48-50.

9. de Mennato $\mathrm{P}$ (2011) La complessità del pensiero di cura.

10. Marini MG, Arreghini L (2012) Medicina narrativa per una sanità sostenibile, Brossura, Milano.

11. de Mennato P (2011b) Introduzione. In: Ferro Allodola V, Canocchi E (Eds.) Prevenzionee cura. Lavorare con le rappresentazioni, Pensa Multimedia, Lecce, p.11. 
12. Mezirow (1991) Transformative Dimensions of Adult Learning, JosseyBass Inc.

13. Charon (2006) Narrative Medicine. Honoring the Stories of Illness, Oxford University Press, Oxford.

14. Gadamer HG (1994) Dove si nasconde la salute, Raffaello Cortina, Milano.

15. Canocchi E (2011) La cura. In: Ferro Allodola V., Canocchi E (Eds.) Prevenzione e cura. Lavorare con le rappresentazioni, Pensa Multimedia, Lecce, p. 159.
16. Freeman WJ (2001) How Brains Make Up Their Minds, Columbia University Press, New York.

17. de Mennato $P$ (2011) La complessità del pensiero di cura. op. cit., p. 33.

18. Galimberti U (2006) La casa di Psiche, Feltrinelli, Milano.

19. Zannini L (2001) Salute, malattia, cura, FrancoAngeli, Milano, p. 44. 